\title{
História pública, ensino de história e educação antirracista ${ }^{1}$
}

Public History, History Teaching and Anti-racist Education

Martha Abreu*

Hebe Mattos**

Keila Grinberg ${ }^{\star * *}$

\section{Resumo}

O artigo reúne reflexões e resultados no campo da pesquisa, da história pública e do ensino de história, que permitem subsidiar estratégias e atitudes de combate ao racismo. Destaca e valoriza a construção de parcerias entre a universidade, a escola e as comunidades negras.

Palavras-chave: história oral; história pública; patrimônio cultural afro-brasileiro; protagonismo negro; combate ao racismo.

\section{Abstract}

The article brings together reflections and results in the field of research, public history and history teaching, which allow subsidizing strategies and attitudes to combat racism. It highlights and values the building of partnerships between the university, the school and the black communities.

Keywords: oral History; public History; Afro-Brazilian cultural heritage; black protagonism; fight against racism.

Nos últimos 15 anos, tem havido grande esforço de historiadores e professores de história no sentido de produzir reflexões sobre o passado escravista, o período do pós-abolição e o patrimônio cultural afro-brasileiro. Esse impulso, que gerou importantes inovações didáticas e historiográficas, vem acontecendo tanto por conta das mudanças introduzidas no ensino de História nas

\footnotetext{
* Universidade Federal Fluminense (UFF), Niterói, RJ, Brasil. Professora titular. marthacabreu@ gmail.com

** Universidade Federal de Juiz de Fora (UFJF), Juiz de Fora, MG, Brasil. hebe.mattos@ gmail.com

*** Universidade Federal do Estado do Rio de Janeiro (UniRio), Rio de Janeiro, RJ, Brasil. keila@pobox.com
} 
escolas e nas universidades desde o fim da ditadura militar no Brasil, quanto, mais especificamente, a partir da promulgação da Lei 10.639/2003, que tornou obrigatório o ensino de História da África e da Cultura Afro-brasileira. ${ }^{2}$ Bons exemplos desse movimento são a elaboração de livros didáticos e material paradidático renovados, com espaço para temáticas relativas à história africana, indígena e afro-brasileira, e o grande número de dissertações sobre o tema produzidas no âmbito do mestrado profissional em Ensino de História, o ProfHistória, programa de pós-graduação que desde 2014 congrega universidades de todo o país ${ }^{3}$ (Janz; Cerri, 2018; Nazario, 2016; Almeida; Grinberg, 2009).

Neste artigo, com o objetivo de contribuir para o aprofundamento dessa reflexão a partir da nossa experiência de pesquisa com a metodologia da história oral e com o desenvolvimento de projetos de história pública, destacaremos algumas possibilidades de envolvimento das escolas e do ensino de história com o patrimônio cultural afro-brasileiro, em relação direta com seus detentores: os grupos culturais e políticos negros. Buscaremos também refletir sobre caminhos de atuação de professores de história no fortalecimento da diversidade étnico-racial e cultural e no combate ao racismo, em diálogo com a incorporação de interpretações sobre a escravidão e o pós-abolição que levem em conta o protagonismo da população negra. A principal estratégia é oferecer para professores, alunos e gestores do campo educacional reflexões sobre resultados e experiências de um amplo projeto de história oral sobre memória e música negra, desenvolvido sob coordenação de Martha Abreu e Hebe Mattos desde 2005 no Laboratório de Historia Oral (LABHOI) do Instituto de História da Universidade Federal Fluminense (UFF), e que hoje tem importantes desdobramentos no campo da História Pública com a parceria de Keila Grinberg (Numem/UniRio).

Esse longo trabalho de pesquisa com comunidades quilombolas e jongueiras do estado do Rio de Janeiro resultou num acervo audiovisual de quase duzentas horas de depoimentos com detentores de patrimônios culturais, de tradições orais e de narrativas históricas ligadas às memórias do cativeiro. Parte grande desse material está disponível livremente no Acervo UFF Petrobrás Cultural - Memória e Música Negra, no LABHOI, disponível no endereço http:// www.labhoi.uff.br/acervo/jongos, ${ }^{4}$ podendo ser consultado por regiões/locais do estado do Rio de Janeiro ou pelo nome das personagens entrevistadas. 
Seguindo a trilha da história oral, o Acervo é formado por registros audiovisuais sobre a memória e a trajetória dos grupos descendentes da última geração de escravizados no Vale do Paraíba fluminense e de suas atividades festivas e musicais. Realizamos, principalmente ao longo de 2007, entrevistas filmadas e organizamos genealogias, reconstituídas com base nos depoimentos orais. Quando possível, levantamos registros de nascimento, óbitos e inventários das antigas fazendas. O roteiro de pesquisa envolveu entrevistas com os mais antigos e com os principais jongueiros, foliões de reis ou calangueiros das comunidades visitadas. Tentamos articular história social com história cultural e política; genealogias familiares com patrimônio cultural. Realizamos também filmagens das principais festas, manifestações musicais e encontros políticos.

Os depoimentos, registrados em diferentes e distantes locais - do sul ao norte do estado do Rio de Janeiro, do interior ao litoral -, evidenciavam a relação do grupo com a memória da escravidão e com as lutas do pós-abolição. ${ }^{5}$ Em todos eles, muita emoção e lágrimas em histórias de vida que vinham à tona com lembranças familiares, saudades de amigos, tempos da infância, festas, momentos de alegria e momentos de dor e sofrimento. Em todos os depoimentos, a força da comunidade negra descendente das senzalas dos vales do café se faz presente. A história e a memória da escravidão também emergem da tradição oral, em contos, versos e performances de descendentes da última geração de africanos escravizados por todo o Brasil. ${ }^{6}$

Para além do Acervo, o projeto também produziu quatro filmes de pesquisa: Memórias do Cativeiro (2005), Jongos, Calangos e Folias - Música Negra, Memória e Poesia (2007), Versos e Cacetes - O Jogo do Pau na Cultura Afro-fluminense (2009) e Passados Presentes - Memória Negra no Sul Fluminense (2011), todos disponíveis em meio digital (www.labhoi.uff.br/passadospresentes), e quatro roteiros de turismo de memória, construídos entre 2013 e 2015, disponíveis em site próprio e em aplicativos para celulares sobre o Quilombo São José da Serra, o Quilombo do Bracuí, o Jongo de Pinheiral e a Pequena África (http://passadospresentes.com.br/site/Site/index.php). Para a fase do projeto realizada a partir de 2013, que demanda contatos e diálogos com as comunidades analisadas com mais profundidade adiante, registrou-se a parceria de Keila Grinberg.

Os filmes de pesquisa, editados com base nas entrevistas realizadas em sua maior parte com uma única câmera de filmagem, podem ser considerados 
como uma escrita videográfica feita por historiadores (filmes historiográficos), já que foram produzidos a partir dos acervos/arquivos audiovisuais da pesquisa (Mattos; Abreu; Castro, 2017). Com roteiro narrativo baseado nos resultados da pesquisa histórica desenvolvida, além de imagens, músicas e danças, que potencializam o impacto, as sensibilidades, as emoções e o alcance de público, esses filmes tornam-se também um efetivo instrumento para envolvermos alunos e professores nos caminhos da diversidade cultural e na narrativa de histórias e memórias sensíveis, até então esquecidas da história oficial, mas não menos fundamentais para a construção de uma história que inclua todos os brasileiros.

Por sua vez, os roteiros de turismo de memória permitem aos alunos e visitantes conhecer e visitar, virtual ou presencialmente, os locais de memória e os narradores das comunidades negras que participaram do projeto, da criação dos memoriais e dos aplicativos para celulares. O filme com o making of do projeto, Criando Passados Presentes, também disponível on-line, tem duração de 23 minutos e é de fácil utilização em sala de aula.

\section{REgISTROS ORAIS E IMPACTOS NA PESQUISA E NO ENSINO DE HISTÓRIA}

O uso da metodologia da história oral em abordagens acadêmicas sobre a história do tempo presente e história da memória, assim como para a história de comunidades e grupos tradicionais, é um campo já consolidado das ciências sociais. O trabalho do Laboratório de História Oral e Imagem da UFF (LABHOI), com as narrativas de camponeses negros de antigas áreas escravistas do Rio de Janeiro, iniciado na década de 1990 e voltado para reconstituir trajetórias de famílias libertas no pós-abolição, trouxe avanços historiográficos muito significativos. ${ }^{7}$

Como imaginar, antes do início desse projeto, que iríamos descobrir, com tantos recorrentes detalhes narrativos, a vigorosa memória do campesinato negro sobre a última geração de africanos trazidos ilegalmente como escravos ao Brasil na primeira metade do século XIX, e novas evidências do tráfico ilegal de africanos no litoral Norte e Sul fluminense? Ou que iríamos conseguir contar histórias desconhecidas da escravidão a partir da memória, da tradição oral e do patrimônio cultural construído pelos descendentes de jongueiros de várias regiões? Entre elas, histórias de violências de poderosos senhores e de 
inteligentes respostas de seus escravizados; relatos sobre fugas e lutas pela terra; metáforas sobre noções de liberdade e direitos; narrativas sobre a abolição com críticas e irreverências dirigidas aos senhores, e relatos sobre a astúcia dos jongueiros e de seus familiares.

Foi mesmo impressionante acompanhar, em visitas a várias comunidades negras e quilombolas no estado do Rio de Janeiro, a força do patrimônio jongueiro. ${ }^{8}$ Como prática social, expressão política e memória cultural, o jongo e os jongueiros de hoje desafiaram todos os projetos das autoridades policiais e religiosas, assim como as previsões dos folcloristas que, desde o final do século XIX, apostavam no seu desaparecimento com o dos últimos africanos (Mattos; Abreu, 2007).

A localização atual do jongo coincide com os lugares de entrada ilegal de africanos escravizados, após a lei de 1831, e com a vasta região das antigas plantações de café do Sudeste. Comunidades jongueiras, algumas delas quilombolas, como Bracuí e São José da Serra, marcam hoje o que foi no passado o movimento de desembarque e de migração forçada dos últimos africanos escravizados que aportaram no Brasil: dos portos clandestinos no litoral Sul e Norte fluminense para o Vale do Paraíba e suas grandes plantações de café, ao longo do século XIX. Nessas plantações, milhares de africanos escravizados, vindos principalmente da África Central, criaram as riquezas do Brasil e deram a base para a consolidação política do Império, com seus barões e projetos de civilização europeia nos trópicos. Mas jamais esqueceram seus valores e tradições contados e recontados de geração em geração.

Para o período do pós-abolição, os resultados da pesquisa não foram menos impactantes. Ajudam a preencher o enorme vazio deixado pela historiografia, até pouco tempo atrás, sobre o destino dos descendentes de escravizados após a abolição. ${ }^{9}$ Além dos muitos descendentes de africanos que encontramos habitando locais próximos aos do cativeiro de seus antepassados, também conseguimos acompanhar relatos sobre as migrações de famílias inteiras em busca de melhores condições de vida, que passaram a morar em outras fazendas, em cidades próximas, como Barra do Piraí e Nova Iguaçu, ou na cidade do Rio de Janeiro, capital da recém-proclamada República.

$\mathrm{Na}$ descrição desses movimentos, foram recorrentes depoimentos sobre o duro trabalho camponês, sobre a importância do respeito aos mais velhos e sobre a alegria dos encontros festivos - especialmente com jongos, calangos, 
folias e jogos de pau - base da construção de sua autoestima e identidade negra. Percebemos ainda a força de suas famílias, herdeiras da solidariedade tecida entre a comunidade escrava do século XIX e escudos protetores na luta cotidiana pela sobrevivência e na defesa contra o racismo, frequentemente presente em relatos sobre a violência, exclusão e guetificação que sofreram ao longo do século XX.

No campo cultural, destacamos também a nossa surpresa pela densidade da herança centro-africana entre os descendentes de escravizados entrevistados, entendida até então apenas como sobrevivências pouco coerentes e esparsas do passado. Fortalecendo a discussão mais ampla sobre a presença da África no Brasil e nas Américas, essa herança começou a ser decifrada, especialmente por Robert Slenes, na performance do jongo, em seus tambores, no fogo, na roda, nos pontos (versos) irônicos e críticos em desafio, no vocabulário e simbologia dos versos, na presença do solista e do coro, na força de princípios cosmológicos da África Central ou na reverência constante aos antepassados e mais velhos (Slenes, 2007; Souza, 2001).

Robert Slenes acompanhou algumas de nossas visitas e pôde observar a recriação desse legado não como nostalgia, mas como patrimônio cultural e bandeira de luta por direitos e contra o racismo, especialmente entre as mais novas gerações de jongueiros. Sem dúvida, como já destacaram Richard Price e Sidney Mintz, não se pode desprezar o potencial de criatividade e transformação dos escravizados e seus descendentes frente às novas condições de vida e trabalho (Price, 2003; Canclini, 1994; Abreu; Assunção, 2018). ${ }^{10}$ Entre as formas de resistência, para além da força da tradição, é preciso levar em conta as inovações, trânsitos culturais e estratégias para o reconhecimento de sua presença na sociedade brasileira na música, na performance e na festa. Aprendemos na prática das entrevistas, do convívio e do diálogo com descendentes de escravizados que as culturas negras precisam sempre ser articuladas com os sujeitos sociais que as produzem. É a atuação dos sujeitos sociais no campo cultural que define o jogo da tradição e mudança, afirmação e identidade.

Nesse sentido, para além dos jongos com fortes referenciais centro-africanos, nossos entrevistados, em diferentes comunidades negras do estado do Rio de Janeiro, também nos relataram suas profundas ligações com as católicas folias de reis e com o ritmo mestiço dos bailes calangos, ao som de pandeiros, 
violas e sanfonas. Numa inteligente e irreverente incorporação de diversas heranças, jongos, calangos, folias (não por acaso título de nosso segundo filme) e jogos de pau (tema do terceiro filme) compõem um impressionante complexo cultural, formado por gramática e repertório comuns, construído coletivamente pelas comunidades negras no Sudeste ao longo dos séculos XIX, XX e XXI. Em comum, além da ampla circulação desses gêneros, a estrutura dos versos, dos improvisos e dos desafios, não por acaso presente em diversas regiões da diáspora nas Américas, configurando a forma de cantar, contar e festejar histórias e valores de uma poderosa identidade negra. ${ }^{11}$ Sem dúvida, aprendemos muito mais do que tínhamos imaginado.

Uma de nossas mais empolgantes constatações foi perceber como, após o fim da escravidão, os descendentes de africanos do Vale do Paraíba mineiro, fluminense e paulista, ao migrarem para as grandes cidades, fundaram as maiores e mais modernas instituições culturais do Sudeste do Brasil: as escolas de samba. Se, no Rio de Janeiro, o Império Serrano no morro da Serrinha é um dos melhores exemplos, os morros da Mangueira e do Salgueiro, assim como o bairro de Madureira, também testemunham a formação de comunidades negras ligadas em linha direta com as memórias do cativeiro e com o patrimônio da África central (Abreu; Mattos; Agostini, 2016, p. 39-50; Nogueira, 2007). E esse protagonismo só agora começa a ser devidamente contado, reconhecido e valorizado.

Cada vez que refletíamos sobre o material obtido pela pesquisa, depois de tantas viagens pelo estado do Rio de Janeiro, ficávamos impressionadas com as dimensões e com as consequências da negligência e do esquecimento sobre as histórias dos descendentes de escravizados no Rio de Janeiro e, por extensão, no Sudeste como um todo. Como era possível não sabermos quase nada sobre a história dos últimos africanos e seus descendentes depois da abolição da escravidão?

Nos debates historiográficos e no ensino de história ainda predominava a perspectiva de uma história única do pós-abolição. Ou seja, uma história contada apenas a partir da experiência da marginalização, que realçava o despreparo, o fracasso, a criminalização e a inferioridade dos libertos após o fim da escravidão, reforçando estereótipos racistas e visões centradas no protagonismo de personagens brancos na história do Brasil (Xavier, 2013). 
Nada sobre a força das famílias e parentes dos libertos, das suas redes de solidariedade na vizinhança dos morros, nas sociedades dançantes e nos sindicatos do porto, ou da valiosa riqueza cultural que traziam dos velhos vales do café, capaz de transformar definitivamente a cultura carioca no século XX a partir da criação de patrimônios culturais nacionais, como o jongo e o samba carioca. Dificilmente encontramos em algum texto historiográfico, do ensino ou de divulgação na época dos carnavais, que a invenção das escolas de samba, protagonistas pelo maior espetáculo popular do planeta, deve ser atribuída aos descendentes da África central e escravizados dos vales do café do Sudeste.

Precisamos reconhecer que nossos projetos com as comunidades jongueiras e quilombolas seguiram em frente não apenas em função de nosso interesse acadêmico específico em escravidão/pós-abolição e/ou em cultura e música negra. As próprias comunidades negras se organizaram para levar suas histórias adiante, com apoio de outros especialistas e algumas vezes com acesso direto a financiamentos públicos. As comunidades jongueiras procuram recontar e tornar visíveis suas histórias e patrimônio, independentemente de nossa presença ou interesse.

Desde que começamos a pesquisa mais sistemática sobre o jongo, em 2005, muita coisa aconteceu. Encontros de jongueiros em São Paulo, Rio de Janeiro, Minas Gerais e Espírito Santo mostraram para os próprios a extensão do jongo no Sudeste - suas aproximações e diversidades - após o recebimento, em 2005, do título pelo Instituto do Patrimônio Histórico e Artístico Nacional (Iphan) de Patrimônio Cultural Imaterial do Brasil. Articularam-se no Pontão de Cultura do Jongo e Caxambu, uma rede de comunidades jongueiras associadas ao Iphan, Museu do Folclore e UFF (Universidade Federal Fluminense), e, a partir daí, produziram material didático, sites, outros filmes, pequenos centros de memória, seminários e muitos encontros que viabilizam a sua existência e a produção de uma narrativa autônoma (Monteiro, E., 2016; 2018). Alguns grupos ainda associaram a luta pela valorização do jongo à construção de uma nova identidade quilombola que reivindica acesso à terra e à construção de locais de memória para o jongo e para sua história.

Porém, pouca coisa mudou em relação às duras condições de vida das comunidades negras, jongueiras e quilombolas. São José da Serra finalmente conseguiu a titulação definitiva das terras, em 2015, mas no Bracuí a herança recebida dos Souza Breves em testamento ainda não está em suas mãos. Muitos 
grupos não conseguem estabelecer centros de referência para visitação, nem têm apoio das prefeituras ou secretarias de Cultura, apesar de terem recebido o título de Patrimônio Cultural do Brasil. Mesmo assim, é possível também perceber mudanças e conquistas viabilizadas graças à bandeira cultural do jongo.

A grande novidade é o envolvimento dos jovens das comunidades. Os jongueiros não têm mais medo ou vergonha das perseguições e preconceitos. Sempre que temos a oportunidade de participar de alguma festa, percebemos a presença dos jovens e o orgulho de uma história que começa a ter mais visibilidade. A tradição parece fazer sentido e atualiza-se em função de uma luta contra o racismo e acesso completo aos direitos de todos os cidadãos. $\mathrm{O}$ jongo deixou de ser coisa de velho ou de um passado que não se quer lembrar. Pelo contrário, muitos grupos reaprendem o jongo, criam escolas para crianças e (re)lembram que ele existia em suas famílias, há muito tempo.

\section{DA HISTÓRIA ORAL À HISTÓRIA PÚBLICA}

Vale agora contar com mais vagar nossa última experiência de trabalho colaborativo com as comunidades jongueiras, no projeto Passados Presentes, desenvolvido em 2015.

Em 2012, com apoio do projeto Rota do Escravo: resistência, herança e liberdade da Unesco, o LABHOI organizou o Inventário dos Lugares de Memória do Tráfico Atlântico de Escravos e da História dos Africanos Escravizados no Brasil (Mattos; Abreu; Guran, 2014). Foi de Keila Grinberg a proposta de elaboração de um banco de dados on-line com as informações do inventário, expandindo as informações sobre os grupos detentores dos patrimônios imateriais incluídos no documento, sobretudo quando interessados em desenvolver atividades de turismo comunitário, histórico e cultural (www. passadospresentes.com.br).

A vertente de tecnologia da proposta previa também a elaboração de quatro aplicativos para celular com roteiros de visitação histórica: a antiga "Pequena África", na região portuária da cidade do Rio de Janeiro, no entorno do Cais do Valongo, principal porto negreiro das Américas, reconhecido como Patrimônio da Humanidade pela Unesco; o "Jongo de Pinheiral”, na cidade de Pinheiral, conhecida hoje como Capital do Jongo; o "Quilombo São José" (Valença) e o "Quilombo do Bracuí" (Angra dos Reis). 
Para além do material virtual, ainda havia outra ousadia na proposta. Por iniciativa de Maria de Fátima Santos - a Fatinha, líder do Grupo de Jongo de Pinheiral -, de Antônio Nascimento Fernandes - o Toninho Canecão do Quilombo de São José - e de Marilda de Souza, liderança do Quilombo do Bracuí, propúnhamos erguer três exposições memoriais a céu aberto nos territórios das comunidades parceiras.

O trabalho de curadoria histórica para o desenvolvimento dos três memoriais começou em setembro de 2014, quando realizamos a primeira oficina para identificação dos pontos do circuito de memória do Quilombo do Bracuí, na casa de Marilda de Souza. Na ocasião, nos reunimos para conversar sobre a futura oficina a ser realizada no Quilombo São José, com Toninho Canecão, e sobre os lugares de memória a serem sinalizados na cidade de Pinheiral, com Fatinha, do Centro de Referência do Jongo de Pinheiral. Em novembro de 2014 realizamos a oficina para identificar os lugares de memória do Quilombo São José, com ampla participação dos jovens da comunidade.

O planejamento do que seria exposto, a escolha dos pontos de visitação e até mesmo a conceituação e a narrativa das exposições foram pensados coletivamente, a partir de muitas reuniões, viagens e visitas do grupo de historiadores e da equipe artística às comunidades proponentes. Os textos de história das exposições e roteiros, ainda que autorais, foram construídos em diálogo com as histórias e os desejos que os também curadores quilombolas e jongueiros nos confiaram. É até difícil explicar o quanto o trabalho coletivo e em parceria mudou nossa experiência de historiadoras profissionais. Já não se pode pensar a pesquisa acadêmica de outra forma. ${ }^{12}$

A maior emoção viria, entretanto, na segunda rodada de oficinas do projeto, em maio de 2015. A primeira delas fora realizada no Quilombo São José, apenas 2 dias depois da emissão definitiva da posse do território para a comunidade, em 30 de abril. Nesse dia, os quilombolas tomaram oficialmente posse do território onde viveram seus antepassados. O acontecimento nos fez lembrar como a nossa relação com os quilombolas vinha de longe.

A primeira visita de Hebe havia acontecido em 1998, com a Fundação Cultural Palmares, para fazer a pesquisa que embasou o relatório de reconhecimento do quilombo, redigido naquele ano. Anos mais tarde e muitas visitas depois, no caminho para a realização de entrevistas para o filme Jongos, Calangos e Folias, vimos pela primeira vez, na estrada, uma sinalização oficial 
de local de interesse histórico - com a indicação Quilombo São José. Parecia que a titulação estava finalmente próxima. Ledo engano. Foram precisos mais de 7 anos, como em uma promessa de Folia de Reis, para que o quilombo entrasse plenamente na posse de seu território.

Difícil descrever o que sentimos ao caminhar com Antônio Nascimento Fernandes até o coração da área que permaneceu por longos anos interditada aos quilombolas, para vê-lo decidir que ali seria construído o memorial do projeto e que a placa de interdição, por ele quebrada, estaria exposta na roda. ${ }^{13}$

Ainda naquele mês de maio de 2015, encerraríamos trabalho de curadoria no quilombo do Bracuí e na cidade de Pinheiral, formatando a narrativa expositiva e os circuitos de memória nos três locais. Junho e julho foram meses de trabalho intenso.

Desde a aprovação do projeto, a prefeitura de Pinheiral tornou-se importante parceira, criando o Parque das Ruínas da Fazenda São José do Pinheiro, onde foi erguido o memorial. Do nosso lado, uma equipe maravilhosa de artistas, designers, artesãos e engenheiros foi aos poucos trazendo a exposição e o aplicativo do sonho para a realidade. Imagens e textos idealizados dentro de um computador materializaram-se nas placas de sinalização e nos grandes painéis da exposição. Ruínas cobertas de vegetação foram limpas e iluminadas para receber a roda expositiva, dando origem a um belo parque, onde foi erguido - feito de pau a pique, madeira, história, memória e arte - o primeiro memorial Passados Presentes.

Aproveitando as boas energias da festa de Santana da cidade de Pinheiral e a presença dos quilombolas do Bracuí e de São José da Serra nas comemorações do dia estadual do jongo, em 26 de julho de 2015 foram inaugurados o memorial e uma versão de teste do primeiros aplicativo. Em Pinheiral, a exposição e o circuito de memória abordam a história do jongo e do pós-abolição no estado do Rio de Janeiro pela experiência dos jongueiros da cidade. ${ }^{14}$

O lançamento em Pinheiral foi apenas o início de um processo. As exposições memoriais no quilombo do Bracuí e no quilombo de São José possuíam, cada uma, narrativas próprias, evocando o tráfico negreiro clandestino e a as raízes africanas do jongo, além de seus museus de percurso, materializados nos circuitos de memória dos territórios quilombolas.

Em 19 de setembro comemoramos com feijoada e roda de jongo a inauguração do memorial e circuito Passados Presentes no quilombo São José. O 
memorial do quilombo São José conta a saga de Tertuliano e Miquelina e de Pedro e Militana, antepassados dos atuais moradores, desde a África até o Brasil. Narra também a luta de seus descendentes pelo território quilombola ocupado ainda no século XIX e a força da tradição cultural do Jongo, que tem origem na África Central.

A sinalização realizada pelo projeto Passados Presentes permite aos visitantes ouvir diversos pontos de jongo e ter acesso às narrativas dos quilombolas mais antigos. Seguindo o roteiro no aplicativo, é possível também realizar percursos mais longos, de grande interesse histórico e ecológico, que incluem o museu comunitário da Casa Quilombola, o centenário pé de jequitibá, a cachoeira saudada nos pontos de jongo e as ruínas do engenho velho. ${ }^{15}$

A festa de inauguração da terceira exposição do projeto aconteceu finalmente no dia 14 de novembro, no Quilombo do Bracuí. A celebração foi memorável, reunindo mais de quatrocentas pessoas. Foi organizada com brilho pela comunidade quilombola que luta há mais de cem anos pelo território coletivo ocupado por seus antepassados, que o receberam oficialmente, em 1878, em doação no testamento de José de Souza Breves, que ali desenvolvia atividades de contrabando na primeira metade do século XIX.

As fazendas de recepção de escravizados se desenvolveram no litoral das principais áreas escravistas do Império do Brasil, sobretudo depois da primeira proibição formal do comércio de cativos africanos no então jovem país independente, em 1831. Elas substituíram as antigas áreas oficiais voltadas para esse tipo de atividade, como o complexo do Valongo, no Rio de Janeiro. Os griôs do Quilombo do Bracuí são guardiões da memória das condições de extrema fragilidade em que chegavam os africanos e da recuperação dos que sobreviviam para serem enviados serra acima para trabalhar nas áreas cafeicultoras do Vale do Paraíba. A tradição oral guardou até mesmo a história do naufrágio criminoso, em águas próximas à fazenda, do brigue negreiro Camargo, perseguido pela marinha brasileira após a segunda lei de extinção do tráfico atlântico, em 1850. O naufrágio deixou documentos históricos nos arquivos da Auditoria da Marinha e no Ministério da Justiça brasileiros. O memorial do quilombo do Bracuí homenageia os africanos sobreviventes resgatados pelas autoridades.

Na roda expositiva, a griô quilombola Marilda de Souza pôde contar essa história para os estudantes que participaram da festa de inauguração. Com os 
jovens do quilombo, ela transforma a tradição oral em bandeira de luta por novos e melhores tempos, simbolizados na imagem da Santa Rita Black, do artista Lee27, exposta no Memorial. A exposição conta a história de como funcionavam as antigas fazendas negreiras do litoral Sul fluminense e de como elas se tornaram improdutivas após o fim do tráfico atlântico de escravos para o Brasil. De fato, os trabalhadores escravizados ali residentes eram testemunhas de um crime contra as leis do Brasil, que apenas após 1850 passou a ser efetivamente reprimido pelas autoridades imperiais. O proprietário da antiga fazenda do Bracuí, José de Souza Breves, alforriou os trabalhadores da fazenda, em 1879, e legou a eles o usufruto das terras, tornando-os herdeiros oficiais do território ocupado. A tradição oral de seus descendentes, no século XXI, tornou-se testemunho de um crime não apenas contra as leis do Império do Brasil como também contra a humanidade.

O memorial conta também a história da luta da comunidade pela terra coletiva ao longo do século XX. Na década de 1970, a construção da rodovia Rio-Santos lhes tirou, não sem luta, toda a terra que ocupavam da estrada até o mar. Ainda hoje, o território comunitário continua ameaçado, apesar da certificação da Fundação Palmares como comunidade quilombola. Três das placas do projeto Passados Presentes foram arrancadas poucas horas após terem sido colocadas. Tais locais de memória continuam sinalizados no roteiro do aplicativo e, felizmente, encontram-se fora da área que vem sendo negociada com o Incra para demarcação definitiva. Esperamos que isso possa se realizar algum dia. Enquanto não acontece, a sinalização do projeto Passados Presentes atualiza a memória do território histórico ocupado pela comunidade e a fortalece para a futura titulação.

\section{O Gente presta atenção na história que eu vou contar}

Deitei minha cabeça na cabeceira do rio mas o pé está lá no mar.

(Ponto de jongo sobre a extensão das terras do Quilombo do Bracuí, de Marilda de Souza)

\section{DiÁlogos, CONVERSAS E VISITAS}

Há outra dimensão do nosso aprendizado que precisa ser valorizada e mais bem compreendida: o convívio com as comunidades negras na sua luta 
cotidiana contra o racismo e na construção de percepções de si como detentores de reconhecidos patrimônios culturais nacionais.

A partir de nossas visitas e dos diversos encontros entre os detentores e nossos alunos (encontros que organizamos ou para os quais fomos convidadas), passamos a perceber que essas aproximações, envolvidas em emoções e sensibilizações, sempre transformavam os envolvidos. Criavam empatias e solidariedades entre todos, desmontavam visões preconcebidas e questionavam estereótipos.

O diálogo estabelecido entre detentores de patrimônios culturais, no caso os jongueiros, alunos universitários, jovens e crianças em idade escolar, tem o poder de modificar a visão dos ouvintes ou visitantes sobre o papel histórico desempenhado pela população negra; os saberes comunitários surpreendem e deixam escancaradas as lacunas dos conteúdos eruditos e livrescos; os sentidos da história e da história pública se ampliam e passam a ser percebidos na própria experiência da conversa ou da visita. Em qualquer nível de ensino, os alunos conseguem se aproximar da metodologia de trabalho do historiador com os registros orais, com a realização de entrevistas e, posteriormente, com a construção de acervos, filmes, exposições e publicações. A experiência de ouvir e sentir outras histórias permite que todos os envolvidos compreendam as noções de direito à história e direito à memória (Mattos; Abreu, 2016).

Sim, todos crescem nesse diálogo e nessas conversas. Quilombolas e jongueiros aprenderam muito, também, ao se relacionarem com pesquisadores, professores e alunos. Aprenderam a conhecer um pouco da universidade e a se apropriar de seus poderes e saberes. Marilda Souza, liderança do Quilombo do Bracuí e guardiã das memórias do Bracuí, afirma, com autoridade, que a comunidade sempre havia feito história oral e que o conteúdo dessa história precisava estar presente nas escolas próximas. Foi profunda também a sua percepção sobre a presença da universidade, ao comentar que nossa visita com os alunos deveria ser feita em ônibus identificados com letras da UFF. A importância da universidade daria visibilidade à comunidade na região de Angra dos Reis, já que pesquisadores frequentemente ali estavam presentes.

Por sua vez, muitos jovens quilombolas, incentivados por outros jovens universitários, animaram-se para buscar o caminho da academia. ${ }^{16} \mathrm{Com}$ as visitas e os convites que começaram a receber de escolas, públicas e privadas, membros das comunidades fortalecem suas narrativas e sua identidade; 
construíram novas alianças locais e novos caminhos de afirmação (algumas vezes também de sustentabilidade, com o turismo, por exemplo) perante diferentes esferas de poder regionais.

Com base em nossa experiência, gostaríamos de recomendar, com muita ênfase, que as escolas se abram mais sistematicamente aos guardiões de memórias, aos detentores dos patrimônios e às lideranças de comunidades negras próximas, como muitos professores já fazem, a partir de iniciativas próprias (exemplos são Silva, 2016, e Ferreira, 2016). As aulas podem incorporar suas histórias e seus patrimônios, rompendo a invisibilização constantemente imposta, mediante convites para rodas de conversa. As escolas podem incentivar a visita a comunidades quilombolas e portadoras de saberes tão importantes quanto os que se encontram nas universidades. Se nada disso for possível, que a escola leve para seus espaços as pesquisas, os acervos e os filmes de história oral que divulgamos, ouvindo e valorizando os saberes dos mestres e representantes das histórias e culturas negras no Brasil. Sem dúvida, muitos professores já tomam essa iniciativa e recebem apoio de suas escolas, mas vale incorporar a perspectiva da troca e do reconhecimento do valor desses detentores de forma definitiva.

Para Junia Pereira e Luciano Roza, autores interessados na presença de congadeiros e foliões de reis nas escolas de Minas Gerais, a estratégia das rodas de conversa em sala de aula é um ótimo caminho de aproximação. Central na experiência histórica dos afro-brasileiros, a conversa em roda e o ato da fala/ escuta valorizam as biografias e as narrativas dos palestrantes. A própria roda é um "desenho ritual", onde diferentes sujeitos podem se encontrar, se ver, "pensar, sentir e se emocionar com as práticas culturais afro-brasileiras, e com as lutas e afirmações que elas convocam" (Pereira; Roza, 2012, p. 95; Pereira, 2012). O orgulho dos detentores pelos seus patrimônios e histórias certamente contagia as rodas de conversa e contribui para que nossos alunos descubram ou se reconheçam na beleza dessas performances, sons, instrumentos, gestos e saberes.

As escolas, os professores e alunos do ensino básico podem e devem participar e experimentar dessas variadas formas de aproximação, escuta, relação e aprendizado. O contato com comunidades quilombolas e o aprendizado com lideranças negras no campo cultural e político também permitem o reconhecimento dos saberes e protagonismos das populações negras, a compreensão 
da importância da diversidade cultural no mundo atual e a vivência de respeito aos direitos culturais de grupos historicamente excluídos e inferiorizados. ${ }^{17}$ Abrem também um amplo caminho de reeducação das relações raciais à medida que os exemplos de confiança e autoestima transmitidos pelos mestres negros invertem as inferiorizadas e empobrecidas imagens ligadas ao folclore e à marginalização da cultura negra. ${ }^{18}$

Um dos melhores momentos, mas, evidentemente, não o único, para se visitar uma comunidade negra é o de uma festa de jongo, dos congados ou dos maracatus. Além de toda a comunidade estar reunida em dia tão especial para o grupo, a festa oferece uma linguagem pública das mais envolventes pela sua performance, música, versos e muitas energias. É o momento em que a comunidade quer ser visível, encena com muito orgulho uma longa luta histórica pela afirmação de seu direito de festejar, divertir-se e se encontrar a partir de seus próprios valores e devoções. Sabemos como, historicamente, as festas populares e negras foram perseguidas, guetificadas e proibidas. Se acontecem hoje é porque muitos antepassados lutaram por elas e não deixaram de transmiti-las para as gerações seguintes. A festa é um efetivo exercício de cidadania, um direito dessas comunidades.

Jongos, como também maracatus, sambas de roda, bois e cocos receberam o importante título de Patrimônios Imateriais do Brasil pelo Instituto do Patrimônio Histórico e Artístico Nacional (Iphan) com base em direitos assegurados pela Constituição de 1988 e pelo Decreto 3.551, de 4 de agosto de 2000 . Isso significa que essas expressões afro-brasileiras foram reconhecidas como representantes legítimos da história e cultura nacionais, pois reúnem tradições, performances e conhecimentos que dizem respeito aos formadores da nação brasileira. Não podem ser esquecidos; precisam ser protegidos e incentivados pelas diversas agências do Estado brasileiro.

Se os patrimônios culturais do Brasil de "pedra e cal", como as cidades históricas e as construções barrocas, demandam preservação e valorização, as expressões imateriais das culturas negras e principalmente seus detentores precisam ser percebidos, ouvidos, respeitados e visitados (Olender, 2017; Lima, 2018). Como mostrou Elaine Monteiro, os grupos detentores dos patrimônios imateriais negros no Brasil, especialmente os jongueiros analisados pela autora, tiveram suas histórias marcadas pelo racismo, pela desigualdade e vulnerabilidade social e econômica. A valorização de seu patrimônio deve vir 
acompanhada por ações de reparação e reconhecimento, mas também de sustentabilidade para toda a comunidade (Monteiro, E., 2018; Canclini, 1994.

A escola pode ocupar importante papel nas ações de salvaguarda dos patrimônios culturais populares. Há muito tempo ela é fundamental para a implantação de políticas de educação patrimonial, ensinando aos alunos o desenvolvimento do afeto pelas belezas do passado (Pinheiro, 2017). Por que não pode ter um papel fundamental no reconhecimento e valorização da beleza de bens culturais imateriais presentes hoje nas comunidades negras?

As relações entre intelectuais (pesquisadores e/ou professores) e comunidades negras e populares não são - e nunca foram - das mais fáceis. As diferenças e evidentes desigualdades de saberes e de condições econômicas (muitas vezes também de cor, posto que até há pouco tempo a maior parte dos professores e pesquisadores eram brancos), rapidamente perceptíveis nos primeiros momentos do contato e conversa, constrangem, trazem desconfianças, afastamentos e, por vezes, conflitos. ${ }^{19}$

Os conflitos também podem ter origem nas famílias dos alunos que, por convicções religiosas, se opõem ao trabalho com patrimônios e histórias de descendentes de africanos nas escolas. Bem distante do proselitismo religioso, da doutrinação moral e política, ou da imposição de uma única verdade, o que se pretende com a presença desses personagens e seus conteúdos é criar oportunidades para o exercício da pluralidade de histórias e culturas no dia a dia escolar. Como definem Junia Pereira e Luciano Roza, "o estudo da cultura e da história afro-brasileiras está orientado pelo interesse e por sua relevância histórica, pela investigação da cultura, valorização e positivação cultural, pelo direito à história e pelo dever de memória, como ocorre com outros conteúdos no currículo" (Pereira; Roza, 2012, p. 104).

Depois de mais de 15 anos de convívio com membros de comunidades negras, podemos dizer que valeu muito a pena. A relação dos intelectuais - no nosso caso, três professoras universitárias brancas - com os detentores das expressões culturais populares é um campo de muitos desafios e negociações, mas de intermináveis aprendizados e de criação de novas sensibilidades e afetos, operações fundamentais na construção de nossas relações com todos os patrimônios culturais. ${ }^{20}$

Sem dúvida, nesse diálogo com as comunidades negras precisamos estar preparados, ou melhor, em constante preparo. Os detentores dos patrimônios 
negros são sujeitos políticos, protagonistas da história do Brasil, guardiões de memórias e narradores de histórias pouco divulgadas, mesmo que não tenham tido acesso à educação formal, mesmo que não tenham reconhecimento social e formação escolar/acadêmica. Estarão sempre, como nós, escrevendo e reescrevendo histórias e novas estratégias de vida e de luta.

\section{REFERÊNCIAS}

ABREU, Martha; ASSUNÇÃO, Matthias. Da Cultura popular à cultura negra. In: ABREU, Martha; XAVIER, Giovana; MONTEIRO, Lívia; BRASIL, Eric (org.). Cultura Negra, novos desafios para os historiadores. v. 1. Niterói: Eduff, 2018.

ABREU, Martha; MATTOS, Hebe; AGOSTINI, Camila. Robert Slenes entre o passado e o presente: esperanças e recordações sobre a diáspora africana e cultura negra no Rio de Janeiro. In: RIBEIRO, Gladys S.; FREIRE, Jonis; CHALHOUB, Sidney; ABREU, Martha C. Escravidão e cultura afro-brasileira. Campinas: Ed. Unicamp, 2016.

ALMEIDA, Anita; GRINBERG, Keila. Detetives do passado: oficinas de investigação histórica. Rio de Janeiro: Numen/UniRio, 2009. Disponível em: http://www.numemunirio.org/detetivesdopassado/.

CANCLINI, Nestor G. O patrimônio cultural e a construção imaginária do nacional. Revista do IPHAN, Brasília, n. 23, p. 94-115, 1994.

DANTAS, Carolina; ABREU, Martha; MATTOS, Hebe; LONER, Beatriz; MONSMA, Karl. Histórias do pós-abolição no mundo Atlântico. 3 v. Niterói: Eduff, 2013.

FERREIRA, Carolina B. Isso é coisa de macumba? Elaboração de um material pedagógico de História sobre as religiosidades afro-brasileiras em museus do Rio de Janeiro. Dissertação (Mestrado em Ensino de História) - ProfHistória. Rio de Janeiro, 2016.

GOMES, Nilma Lino. Cultura Negra e Educação. Revista Brasileira de Educação, n. 23, maio/jun./jul./ago. 2003.

JANZ, Caroline; CERRI, Luis Fernando. Treze anos após a Lei n 10.639/03: o que os estudantes sabem sobre a história da África?. AfroÁsia, Salvador: UFBA, n. 57, 2018.

LIMA, Monica. História, patrimônio e memória sensível: o Cais do Valongo no Rio de Janeiro. Revista Virtual Outros Tempos, v. 15, n. 26, 2018.

MATTOS, Hebe; ABREU, Martha. A história como performance: jongos, quilombos e a memória do tráfico ilegal de escravizados africanos. In: MAUAD, Ana Maria M.; ALMEIDA, Juniele R. de; SANTHIAGO, Ricardo. História Pública no Brasil: sentidos e itinerários. São Paulo: Letra e Voz, 2016. 
MATTOS, Hebe; ABREU, Martha. Jongo, registros de uma história. In: MEMÓRIA do Jongo: as gravações históricas de Stanley Stein, Vassouras, 1949. (ed. Silvia H. Lara). Rio de Janeiro: Folha Seca; Campinas: Cecult, 2007.

MATTOS, Hebe; ABREU, Martha; CASTRO, Isabel. Da história oral ao filme de pesquisa: o audiovisual como ferramenta do historiador. História, Ciências, Saúde Manguinhos, Rio de Janeiro, v. 24, n. 4, p. 1147-1160, out./dez. 2017.

MATTOS. Hebe; ABREU, Martha; GURAN, Milton. Por um história pública dos africanos escravizados no Brasil. Revista Estudos Históricos, Rio de Janeiro, v. 27, n. 54, p. 255-273, 2014.

MONTEIRO, Elaine. Branco quer aprender dança de preto: valorização e reconhecimento no registro do patrimônio imaterial afro-brasileiro. In: ABREU, Martha; XAVIER, Giovana; MONTEIRO, Lívia; BRASIL, Eric. Cultura Negra, novos desafios para os historiadores. v. 1. Niterói: Eduff, 2018.

MONTEIRO, Elaine. Universidade e comunidade: diálogos de saberes e fazeres em ações de salvaguarda do patrimônio imaterial. In: MATTOS, Hebe (org.). História oral e comunidade, reparações e culturas negras. São Paulo: Letra e Voz, 2016. p. 73-94.

MONTEIRO, Lívia N. Reis negros na escola: festas de Congada e o ensino de História do pós-Abolição no Brasil. In: XAVIER, Giovana (org.). Histórias da Escravidão e do Pós-Abolição para as escolas. Cruz das Almas: Ed. UFRB; Belo Horizonte: Fino Trato, 2016. p. 277-292. (Coleção Uniafro).

NAZARIO, Lorraine Janis V. dos S. A lei e os livros: transformações na produção didática de História após a Lei 10.639/03. Dissertação (Mestrado em Ensino de História) - ProfHistória. Rio de Janeiro, 2016.

NOGUEIRA, Nilcemar. Dossiê das Matrizes do Samba Carioca. Rio de Janeiro: Centro Cultural Cartola; Iphan/MinC, 2007. Disponível em: http://portal.iphan.gov.br/ uploads/ckfinder/arquivos/Dossi-\%20Matrizes\%20do\%20Samba.pdf.

OLENDER, Marcos. O afetivo efetivo: sobre afetos, movimentos sociais e preservação do patrimônio. Revista do Iphan, Brasília: MinC, n. 35, p. 321-341, 2017.

PEREIRA, Amilcar. "Por uma autêntica democracia racial!": os movimentos negros nas escolas e nos currículos de história. Revista História Hoje, São Paulo: Anpuh, v. 1, n. 1, p. 111-128, 2012.

PEREIRA, Junia S.; ROZA, Luciano M. O ensino de história entre o dever de memória e o direito à história. Revista História Hoje, São Paulo: Anpuh, v. 1, n. 1, p. 89-110, 2012.

PINHEIRO, Maria Lucia B. Trajetória das ideias preservacionistas no Brasil, 19301940. Revista do Iphan, Brasília, n. 35, p.13-31, 2017.

PRICE, Richard. O Milagre da crioulização: retrospectiva. Estudos afro-asiáticos, Salvador: UFBA, v. 25, n. 3, p. 383-419, 2003. 
SILVA, Joana D’Arc de Araujo. Enegrecendo as Belas Artes: ensinando história por meio das trajetórias de dois pintores negros do Rio de Janeiro na segunda metade do século XIX. Dissertação (Mestrado em Ensino de História) - ProfHistória. Rio de Janeiro, 2016.

SLENES, Robert. "Eu venho de muito longe. Eu venho cavando": jongueiros cumba na senzala centro-africana. In: MEMÓRIA do Jongo: as gravações históricas de Stanley Stein, Vassouras, 1949. (ed. Silvia H. Lara). Rio de Janeiro: Folha Seca; Campinas: Cecult, 2007.

SOUZA, Marina de Mello e. Reis negros no Brasil escravista: história da festa de coroação de rei congo. Belo Horizonte: Ed. UFMG, 2001.

VILHENA, Luís Rodolfo da P. Projeto e missão: o movimento folclórico brasileiro (1947-1964). Rio de Janeiro: Ed. FGV: Fundação Nacional de Arte, 1997.

XAVIER, Giovana. "Já raiou a liberdade": caminhos para o trabalho com a história do pós-abolição na educação básica. In: PEREIRA, Amilcar; MONTEIRO, Ana Maria (org.). Ensino de História e Culturas Afro-Brasileiras e Indígenas. Rio de Janeiro: Pallas, 2013.

\section{NOTAS}

${ }^{1}$ Este artigo é um desdobramento de nosso texto "História oral e Educação Antirracista", a ser publicado em 2019 no livro História Oral e Educação, organizado por Juniele Rabêlo de Almeida e Everardo Paiva de Andrade pela Ed. Letra e Voz.

${ }^{2}$ Em 2008 a lei foi reformada, incluindo também a história indígena (Lei 11.645/2008).

${ }^{3}$ Ver o banco de dissertações produzidas no âmbito do Mestrado Profissional em Ensino de História (ProfHistória), disponível no site do Programa, em https://profhistoria.ufrj.br/ banco_tese.

${ }^{4}$ O Acervo audiovisual formado a partir de 2007 era continuidade do acervo em áudio do projeto de história oral Memórias do Cativeiro, coordenado por Hebe Mattos e Ana Lugão Rios. Iniciado em 1994, ele é formado com entrevistas genealógicas, em fita cassete, com camponeses negros descendentes da última geração de libertos, que vivera a abolição legal da escravidão no Brasil, em 1888. Esse acervo deu origem ao livro e ao filme Memórias do Cativeiro (2005). A realização do novo projeto (Memória e Música Negra / Petrobrás Cultural) não interrompeu a continuidade da permanente documentação e pesquisa do LABHOI sobre memórias da escravidão no Rio de Janeiro. Com a formação do acervo UFF/ Petrobras Cultural, em 2007, o arquivo passou a incorporar registros audiovisuais.

${ }^{5}$ Para mais informações sobre o projeto, principais etapas, locais de visita, relatos de viagem, documentos consultados, pesquisa bibliográfica e informações sobre as performances, ver: http://www.historia.uff.br/jongos/?page_id=11. 
${ }^{6}$ Para exemplos da força dessas entrevistas, vale assistir aos depoimentos do sr. Sebastião, da comunidade negra e jongueira de Mambucaba; do sr. Manoel Moraes e de Marilda Souza, lideranças do quilombo do Bracuí; do sr. Manoel Seabra, Dona Santinha e Toninho Canecão, do Quilombo São José da Serra; de José Gomes de Moraes (Sr. Juca) e Maria Leite Adelino (Tia Marina), das comunidades negras jongueiras de Barra do Piraí; de Marli Teixeira, de Duas Barras, e do jovem Luis Fernando Cândido (Feijão).

${ }^{7}$ Também foi fundamental na formação de jovens historiadores então estagiários do projeto. Nosso agradecimento especial a Carolina Vianna, Thiago Campos, Carlos Eduardo Costa, Camila Marques, Camila Mendonça, Edmilson Santos, Eric Brasil Nepomuceno, Gilceano Menezes, Liliane Brito, Luana Oliveira, Luciana Leonardo e Matheus Serva.

${ }^{8}$ Também conhecido como caxambu e tambu, o jongo é uma expressão cultural executada por afrodescendentes em várias localidades do Sudeste do Brasil desde o século XIX, apesar das proibições e cerceamentos. Atualmente os jongos apresentam percussão, dança e canto, em forma de poesia e desafio. A dança, próxima da fogueira, é em círculo, no centro do qual os dançarinos evoluem. As memórias dos velhos revelam que a prática do jongo envolve saberes e segredos partilhados por familiares. Os jongos hoje proporcionam a solidariedade comunitária e o orgulho de um patrimônio compartilhado e valorizado. Em 2005 o jongo recebeu o título de Patrimônio Cultural do Brasil. Ver Slenes (2007) e o Dossiê Jongo no Sudeste, coordenado por Elizabeth Travassos, disponível em: http://portal.iphan.gov.br/ uploads/publicacao/PatImDos_jongo_m.pdf.

${ }^{9}$ Nos últimos anos, é importante registrar o significativo crescimento dos trabalhos sobre o pós-abolição, contribuindo para a escrita de uma história do racismo no Brasil (ver, por exemplo, DANTAS et al., 2013).

${ }^{10}$ Entrevistas com Robert Slenes, com a nossa participação e a de Matthias Assunção, podem ser acompanhadas no Acervo, nas fitas 01.0062/0063/0072/0073 (Palavra de Busca: Conferencia).

${ }^{11}$ Vale destacar que os jongueiros, e consequentemente o jongo, ganharam hoje maior visibilidade, especialmente depois do título recebido em 2005, pelo Instituto do Patrimônio Histórico e Artístico Nacional (Iphan), de Patrimônio Cultural imaterial brasileiro. Embora muitos acadêmicos tenham tido participação importante nesse reconhecimento, os próprios jongueiros começaram toda essa história e escolheram o jongo - e não os calangos ou as folias de reis - como canal de identidade, mobilização política e reconhecimento institucional através de ações de salvaguarda (ver MATTOS; ABREU, 2007; MONTEIRO, L., 2016).

${ }^{12}$ Sobre essas viagens, diálogos e trocas, publicamos uma espécie de caderno de campo no blog "conversa de historiadoras". Cf., entre outros: https://conversadehistoriadoras. com/2014/09/08/passados-presentes/ e https://conversadehistoriadoras.com/2014/11/10/ encontros-na-estrada/.

${ }^{13}$ Cf. https://conversadehistoriadoras.com/2015/05/10/um-dia-de-vitoria/.

${ }^{14}$ Sobre a inauguração, cf. https://conversadehistoriadoras.com/2015/07/28/pinheiralcidade-do-jongo/ e https://conversadehistoriadoras.com/2015/07/19/o-dia-estadual-do -jongo-e-o-pos-abolicao-no-rio-de-janeiro/. 
${ }_{15}$ Cf. https://conversadehistoriadoras.com/2015/09/21/noticias-da-inauguracao-noquilombo-sao-jose/ e https://conversadehistoriadoras.com/2015/09/13/memorial -passados-presentes-no-quilombo-sao-jose/.

${ }^{16}$ Nesse sentido, é importante reconhecer o trabalho do Pontão de Cultura do Jongo, coordenado pela professora Elaine Monteiro, da Faculdade de Educação da UFF.

${ }^{17}$ Essa proposta de diálogo e aprendizagem com comunidades negras no Rio de Janeiro e de todo o Brasil aproxima-se do projeto que vem sendo implementado, desde 2010, em algumas universidades brasileiras, conhecido como "Encontro de Saberes". Sob a coordenação de José Jorge de Carvalho, busca incluir saberes de comunidades negras e indígenas nas universidades, de forma equivalente aos saberes acadêmicos, propiciando diálogos interepistêmicos e interculturais. São ministrados cursos equivalentes aos dos saberes acadêmicos, em parceria com professores institucionais, que envolvem seus tradicionais conhecimentos sobre alimentação, agricultura, sustentabilidade e ação política, assim como história, direitos, sistema de valores e patrimônio (ver MONTEIRO, E., 2016, p. 87-92).

${ }^{18} \mathrm{Em}$ geral, os estudos de folclore valorizavam mais as expressões culturais do que seus detentores, buscavam determinar a autenticidade das práticas culturais e não as condições sociais e políticas da continuidade das expressões negras e populares (ver VILHENA, 1997). Sobre a importância da positivação da cultura negra, ver Gomes (2003).

${ }^{19}$ São inúmeras as reclamações de quilombolas e jongueiros em relação ao desrespeito dos pesquisadores e alunos visitantes, que não devolvem suas pesquisas aos entrevistados. Conhecemos comunidades que não mais recebem pesquisadores acadêmicos sem autorização explícita prévia, por sua falta de retorno e comprometimento com as demandas das comunidades. Além disso, são significativas as insatisfações em relação a convites para apresentações nas escolas, universidades, locais de turismo, museus e centros culturais, que não os recebem com os devidos cuidados, seja preparando os visitantes, seja fornecendo condições materiais dignas de transporte e alimentação.

${ }^{20}$ Continuamos renovando as parcerias com comunidades quilombolas e jongueiras. Um dos últimos trabalhos conjuntos foi a produção de um Termo de Ajuste de Conduta (TAC), aplicado à fazenda Santa Eufrásia, em Vassouras, em função da existência de um roteiro de turismo que reforçava o racismo e não valorizava a história dos descendentes de africanos na região (http://www.mpf.mp.br/rj/sala-de-imprensa/noticias-rj/mpf-rj-celebra -acordo-que-poe-fim-a-encenacao-sobre-a-201cescravidao $201 \mathrm{~d}$-para-turistas-emfazenda).

Artigo recebido em 15 de abril de 2019. Aprovado em 23 de julho de 2019. 